\title{
Potential role of differential medication use in explaining excess risk of cardiovascular events and death associated with chronic kidney disease: A cohort study
}

Nisha Bansal ${ }^{1 *+}$, Chi-yuan Hsu ${ }^{1 \dagger}$, Malini Chandra ${ }^{2+}$, Carlos Iribarren ${ }^{2}$, Stephen P Fortmann ${ }^{3}$, Mark A Hlatky ${ }^{3}$ and Alan S Go ${ }^{1,2+}$

\begin{abstract}
Background: Patients with chronic kidney disease (CKD) are less likely to receive cardiovascular medications. It is unclear whether differential cardiovascular drug use explains, in part, the excess risk of cardiovascular events and death in patients with CKD and coronary heart disease (CHD).

Methods: The ADVANCE Study enrolled patients with new onset CHD (2001-2003) who did (N=159) or did not have $(N=1088)$ CKD at entry. The MDRD equation was used to estimate glomerular filtration rate (eGFR) using calibrated serum creatinine measurements. Patient characteristics, medication use, cardiovascular events and death were ascertained from self-report and health plan electronic databases through December 2008.

Results: Post-CHD event ACE inhibitor use was lower (medication possession ratio $0.50 \mathrm{vs} .0 .58, \mathrm{P}=0.03$ ) and calcium channel blocker use higher $(0.47$ vs. $0.38, P=0.06)$ in CKD vs. non-CKD patients, respectively. Incidence of cardiovascular events and death was higher in CKD vs. non-CKD patients (13.9 vs. 11.5 per 100 person-years, $\mathrm{P}<$ 0.001 , respectively). After adjustment for patient characteristics, the rate of cardiovascular events and death was increased for eGFR $45-59 \mathrm{ml} / \mathrm{min} / 1.73 \mathrm{~m}^{2}$ (hazard ratio [HR] 1.47, 95\% Cl: 1.10 to 2.02) and eGFR < $45 \mathrm{ml} / \mathrm{min} / 1.73$ $\mathrm{m}^{2}$ (HR 1.58, 95\% Cl: 1.00 to 2.50). After further adjustment for statins, $\beta$-blocker, calcium channel blocker, ACE inhibitor/ARB use, the association was no longer significant for eGFR $45-59 \mathrm{ml} / \mathrm{min} / 1.73 \mathrm{~m}^{2}$ (HR 0.82, 95\% Cl: 0.25 to 2.66 ) or for eGFR $<45 \mathrm{ml} / \mathrm{min} / 1.73 \mathrm{~m}^{2}$ (HR $1.19,95 \% \mathrm{Cl}: 0.25$ to 5.58 ).
\end{abstract}

Conclusions: In adults with $\mathrm{CHD}$, differential use of cardiovascular medications may contribute to the higher risk of cardiovascular events and death in patients with CKD.

\section{Background}

Cardiovascular diseases remain the leading cause of death in patients with chronic kidney disease (CKD) [1-5]. Potential modification of cardiovascular disease risk through pharmacological interventions is a critical component of current care and prevention in patients with known coronary heart disease (CHD) or at risk for CHD.

\footnotetext{
* Correspondence: nisha.bansal@ucsf.edu

+ Contributed equally

'Department of Medicine, University of California, San Francisco, San

Francisco, CA, USA

Full list of author information is available at the end of the article
}

Observational studies have shown that despite being at high risk for CHD, many patients with CKD or endstage renal disease (ESRD) are less likely to receive cardiovascular medications [6-8]. One study found that among the $35.5 \%$ of CKD patients not taking an angiotensin converting enzyme (ACE) inhibitor, over half did not have clear contraindications to ACE inhibitor use [9]. In certain studies, CKD or ESRD patients hospitalized with acute myocardial infarction were less likely to receive immediate evidence-based therapies such as aspirin, $\beta$-blockers, ACE inhibitors, angiotensin receptor blockers (ARBs) or lipid lowering agents [10-17].

\section{() Biomed Central}

(c) 2011 Bansal et al; licensee BioMed Central Ltd. This is an Open Access article distributed under the terms of the Creative Commons Attribution License (http://creativecommons.org/licenses/by/2.0), which permits unrestricted use, distribution, and reproduction in any medium, provided the original work is properly cited. 
Although previous studies have established that patients with CKD have substantial cardiovascular disease burden [18-20] and are frequently under-prescribed beneficial cardiovascular medications, the potential impact of cardiovascular medications exposure on recurrent cardiovascular events in those with CKD and known CHD is not known. Underuseof cardioprotective medications may be one explanation for the excess cardiovascular morbidity in this at-risk patient population [21]. To address this, we examined whether differential cardiovascular drug use, specifically statins, $\beta$-blockers, calcium channel blockers, ACE inhibitors and ARBs, helps to explain, at least in part, the excess risk of recurrent cardiovascular disease events associated with CKD in a large prospective cohort of patients with known CHD followed longitudinally.

\section{Methods}

\section{Study sample and study design}

The source population included adults (age $\geq 20$ years) who received medical care within Kaiser Permanente of Northern California, a large integrated healthcare delivery system providing comprehensive care to more than $30 \%$ of insured adults in the San Francisco and greater Bay area. Previous studies have shown that the membership is representative of the local surrounding and statewide insured adult population, with the exception of slightly lower proportions of persons at the extremes of age and income level [22]. Adult members of Kaiser between the ages of 45 to 75 years with no prior history of CHD who first presented with new symptoms of CHD (either stable exertional angina or acute myocardial infarction) between October 28, 2001 and December 31, 2003 were enrolled into the Atherosclerotic Disease, VAscular functioN, and genetiC Epidemiology (ADVANCE) Study [23]. Recruitment of study participants, exlusion and inclusion criteria into the ADVANCE study has been described in detail previously [23]. Institutional review boards of the collaborating institutions at Kaiser Permanente Northern California and Stanford University approved the study, and written informed consent was obtained from all study participants.

To identify cases of incident acute myocardial infarction, we identified men aged 45 to 75 years old and women aged 55 to75 years old who had acute myocardial infarction as their first presentation of clinical coronary disease between October 28, 2001 through December 31, 2003 by weekly searches of automated laboratory for elevated cardiac enzymes and hospital discharge databases for primary discharge diagnosis of myocardial infarction (ICD-9-CM code 410). Primary care physicians and patients were screened by telephone interview to confirm the absence of prior diagnosed coronary heart disease, coronary revascularization, or ischemic symptoms more than 14 days before admission for acute myocardial infarction. In addition, electrocardiograms were systematically reviewed to exclude any patients with a prior silent Q-wave myocardial infarction. To identify cases of incident stable exertional angina, we identified men and women aged 45 to 75 years old who had stable exertional angina as their first presentation of clinical coronary disease during this same time period by performing weekly searches of automated ambulatory visit databases for new outpatient diagnoses of angina pectoris (ICD-9-CM 413.x). Primary treating physicians of potential participants were contacted to confirm the occurrence of new onset, stable exertional angina. Patients were similarly screened by telephone interview to confirm the absence of prior coronary heart disease and coronary revascularization. In addition, patients had to report evidence of stable chest pain or chest pressure reproduced by the same level of physical exertion, lasting more than one minute and less than 15 minutes, and responded to rest or nitroglycerin.

We conducted a parallel cohort study of participants of ADVANCE followed from the index date of initial CHD event until December 31, 2008 to assess differential patterns of medication use and rates of recurrent cardiovascular events after an incident CHD event. The exposed group included those with pre-existing chronic kidney disease (CKD), defined as estimated glomerular filtration rate $(\mathrm{eGFR})<60 \mathrm{ml} / \mathrm{min} / 1.73 \mathrm{~m}^{2}$. The unexposed, control group included participants of ADVANCE without pre-existing CKD, and were also followed longitudinally for the same time period.

\section{Measurement of kidney function}

Kidney function was assessed using estimated glomerular filtration rate calculated from the latest serum creatinine measurement prior to the index date. Estimated glomerular filtration rate (eGFR) was estimated using the four-variable abbreviated Modification of Diet in Renal Disease (MDRD) Study equation [24] based on the latest outpatient serum creatinine test result found in health plan laboratory databases prior to the index date [25]. Based on prior work and recent guidelines published by the Kidney Disease: Improving Global Outcomes (KDIGO) Committee, we staged kidney function as (in units of $\mathrm{ml} / \mathrm{min} / 1.73 \mathrm{~m}^{2}$ ): 90 to 130,60 to 89,45 59 , and less than $45[18,26]$. As previously described, serum creatinine values were calibrated to the core laboratory used to generate the MDRD estimating equation [18].

\section{Measurement of medication use}

Medication exposure was obtained from health system pharmacy databases. Medication exposure in days was 
measured from enrollment until death, disenrollment or the end of the study period December 31, 2008. The medication possession ratio (MPR), the number of days of exposure to medication divided by the number of days of follow-up from enrollment date, was calculated for each class of medications (statins, $\beta$-blockers, calcium channel blockers, ACE inhibitors, ARBs) for both the study cohort and controls, which has been validated in previous studies as a summary measure of possible medication adherence [27-29]. If a patient was not prescribed a particular medication class, the MPR was assigned a value of zero.

\section{Covariates}

Data were collected on demographic characteristics, lifestyle factors, cardiovascular and other medical history, family history of coronary heart disease, systolic and diastolic blood pressure, and body mass index [30]. Age at index date was based on self-report and confirmed in health plan databases. Patients also provided selfreported information on gender, race/ethnicity, marital status, employment status, annual household income, parental and sibling history of coronary heart disease, history of prior stroke, peripheral arterial disease, diabetes mellitus, hypertension, smoking status at index date (current, former, or never), alcohol use and intensity of leisure-time activity during the 12 months prior to study visit date. The most recent outpatient systolic and diastolic blood pressure values before index date were obtained from ambulatory visit databases, which have been shown to reliably reflect chronic blood pressure levels in our database [31]. Body mass index $(\mathrm{kg} /$ $\mathrm{m}^{2}$ ) was measured at the study visit using standard procedures.

\section{Outcomes}

The primary outcome was the occurrence of a recurrent cardiovascular disease event (i.e., hospitalization for acute myocardial infarction, angina, coronary artery bypass graft surgery, percutaneous coronary intervention, peripheral arterial disease, revascularization or stroke) identified from hospital discharge diagnosis and billing claims databases using validated International Classification of Diseases, Ninth Edition (ICD-9) codes as well as deaths identified from health plan administrative databases, Social Security Administration vital status files, and California state death certificate registry during follow-up [18]. Case ascertainment was extremely reliable as the majority of events were captured within the health delivery system. The number and type of events were followed for the exposed group with CKD and the unexposed control group without CKD from enrollment until death, disenrollment or the end of the study period on December 31, 2008 which was the latest date with complete death information at the time of analysis. For patients who had more than one event during the follow-up period, the first outcome of its kind was included in the results (e.g. the first occurrence of acute myocardial infarction). Incidence rates were reported in rates per 100 person-years for each event type.

\section{Statistical approach}

All analyses were performed using SAS statistical software version 9.1 (Cary, N.C.). Differences between patients with CKD and without CKD were compared using Student's $t$ test for continuous variables and chisquared test for categorical variables. We performed Cox proportional hazards regression to examine the association between level of pre-event kidney function and the risk of recurrent cardiovascular disease event, with eGFR $\geq 60 \mathrm{ml} / \mathrm{min} / 1.73 \mathrm{~m}^{2}$ as the referent level of kidney function. Variables included in models were based on variables that were significantly different between study population and controls on bivariate analyses or have previously been shown to be associated either with kidney function or cardiovascular disease. Patient demographic characteristics, lifestyle factors and comorbid conditions were added to regression models. MPRs for statins, $\beta$-blockers, calcium channel blockers, ACE inhibitors and ARBs were included in the final model to evaluate whether post-event medication exposure mediated the risk of recurrent cardiovascular events or death in those with CKD.

\section{Results}

The study included 159 patients with CKD and 1088 patients without CKD before their incident CHD diagnosis. Patients with CKD were more likely than those without CKD to be older and women (Table 1). Those with CKD were less likely to engage in moderate or heavy activities compared with the non-CKD group. Mean eGFR was $49.7 \pm 9.8 \mathrm{ml} / \mathrm{min} / 1.73 \mathrm{~m}^{2}$ for those with CKD and $85.0 \pm 17.7 \mathrm{ml} / \mathrm{min} / 1.73 \mathrm{~m}^{2}$ for those without CKD.

Patients with pre-existing CKD were more likely than those without CKD to have a history of stroke, diabetes mellitus and hypertension. Mean body mass index was similar in both groups (Table 1). CKD patients were more likely to have elevated blood pressure compared with patients who did not have CKD (Table 1).

At baseline, only $1.3 \%$ of patients with CKD were at the current guideline-based target blood pressure (defined as $<130 / 80 \mathrm{~mm} \mathrm{Hg}$ for those with CKD or diabetes mellitus and $<140 / 90 \mathrm{~mm} \mathrm{Hg}$ for all others) compared with $1.8 \%$ of those without CKD. At the end of the follow-up period, $30.2 \%$ of those with CKD were at goal blood pressure compared with $19.2 \%$ in non-CKD patients. 
Table 1 Baseline characteristics of ADVANCE subjects with incident coronary heart disease at enrollment by CKD status*

\begin{tabular}{|c|c|c|c|}
\hline Characteristic & CKD ( $N=159)$ & Non-CKD ( $=1088)$ & P Value \\
\hline Mean (SD) Age, year & $66.8(7.9)$ & $61.7(8.3)$ & $<0.001$ \\
\hline Women, \% & 42.8 & 25 & $<0.001$ \\
\hline African American & 6.3 & 3.9 & \\
\hline Mean (SD) prior estimated glomerular filtration rate $\left(\mathrm{ml} / \mathrm{min} / 1.73 \mathrm{~m}^{2}\right)$ & $49.7(9.8)$ & $85(17.7)$ & $<0.001$ \\
\hline Married/Domestic Partner & 66.7 & 75.1 & $<0.001$ \\
\hline Current cigarette smoking, $\%$ & 7.6 & 9.0 & 0.3 \\
\hline Alcohol use in prior 12 months, $\%$ & 67.3 & 69.8 & 0.5 \\
\hline Leisure-time Activity in past 12 months, $\%$ & & & 0.02 \\
\hline Minimal & 42.8 & 31.0 & \\
\hline Light & 12.6 & 18.9 & \\
\hline Moderate & 31.5 & 35.8 & \\
\hline Heavy & 13.2 & 14.3 & \\
\hline \multicolumn{4}{|l|}{ Medical History, \% } \\
\hline Stroke/transient ischemic attack & 17.0 & 9.4 & $<0.001$ \\
\hline Peripheral arterial disease & 13.8 & 9.4 & 0.08 \\
\hline Diabetes mellitus & 34.6 & 26.9 & 0.04 \\
\hline Diagnosed hypertension & 90.6 & 79.5 & $<0.001$ \\
\hline Parental History of Coronary Disease, \% & 45.9 & 51.4 & 0.2 \\
\hline Sibling History of Coronary Disease, \% & 25.8 & 22.9 & 0.4 \\
\hline Mean systolic blood pressure $(\mathrm{mm} \mathrm{Hg})$ & 132.0 & 122.0 & $<0.001$ \\
\hline Systolic (mm Hg), \% & & & $<0.001$ \\
\hline$\leq 120$ & 31.7 & 52.2 & \\
\hline $121-129$ & 19.0 & 18.7 & \\
\hline 130-139 & 16.5 & 13.1 & \\
\hline $140-159$ & 19.0 & 12.3 & \\
\hline $160-179$ & 11.4 & 2.8 & \\
\hline$>180$ & 2.5 & 1.0 & \\
\hline Mean diastolic blood pressure (mm Hg) & 73.0 & 71.1 & 0.02 \\
\hline Diastolic $(\mathrm{mmHg}), \%$ & & & $<0.001$ \\
\hline$\leq 80$ & 81.5 & 84.7 & \\
\hline $81-84$ & 6.4 & 8.5 & \\
\hline $85-89$ & 4.5 & 4.1 & \\
\hline $90-99$ & 4.5 & 2.6 & \\
\hline $100-109$ & 1.9 & 0.2 & \\
\hline$\geq 110$ & 1.3 & 0 & \\
\hline Mean (SD) total cholesterol & $215.2(41.4)$ & $214.9(41.8)$ & 0.9 \\
\hline Mean (SD) LDL cholesterol & $126.9(32.8)$ & $131.7(35.7)$ & 0.2 \\
\hline Mean (SD) HDL cholesterol & $47.2(14.4)$ & $44.5(12.2)$ & 0.02 \\
\hline Mean (SD) triglyceride level & $201.2(139.0)$ & $200.4(130.2)$ & 0.9 \\
\hline Mean (SD) body mass index $\left(\mathrm{kg} / \mathrm{m}^{2}\right)$ & $29.6(5.1)$ & $29.1(5.4)$ & 0.4 \\
\hline
\end{tabular}

${ }^{*}$ CKD indicates chronic kidney disease

At baseline only $0.6 \%$ of those with CKD had an LDL cholesterol level $<70 \mathrm{mg} / \mathrm{dL}$ compared with $1.9 \%$ of those without CKD. At the end of the followup period, $30.2 \%$ of those with CKD achieved an LDL
$<70 \mathrm{mg} / \mathrm{dL}$ compared with $27.0 \%$ of those without CKD.

At the end of the follow-up period, those with CKD achieved a greater reduction in systolic and diastolic 
Table 2 Change in cardiovascular risk factors from baseline to end of follow-up period by CKD status*

\begin{tabular}{cccc}
\hline Characteristic & $\begin{array}{c}\text { CKD } \\
\text { (N = 159) }\end{array}$ & $\begin{array}{c}\text { Non-CKD } \\
\text { (N = 1088) }\end{array}$ & P Value \\
\hline Systolic blood pressure, mean (SD) $(\mathbf{m m ~ H g})$ & $-2.4(22.9)$ & $3.2(21.2)$ & 0.01 \\
\hline Diastolic blood pressure, mean(SD) $(\mathbf{m m} \mathbf{H g})$ & $-2.9(13.2)$ & $0.36(11.6)$ & $<0.001$ \\
\hline Total cholesterol, mean (SD) $(\mathbf{m g} / \mathbf{d L})$ & $-55.9(50.5)$ & $-54.7(43.8)$ & 0.7 \\
\hline LDL cholesterol, mean (SD) $(\mathbf{m g} / \mathbf{d L})$ & $-44.3(39.9)$ & $-46.3(37.1)$ & 0.6 \\
\hline HDL cholesterol, mean (SD) $(\mathbf{m g} / \mathbf{d L})$ & $0.22(11.7)$ & $0.94(9.9)$ & 0.5 \\
\hline Triglycerides, mean (SD) $(\mathbf{m g} / \mathbf{d L})$ & $-37.5(114.4)$ & $-47.4(120.2)$ & 0.4 \\
\hline
\end{tabular}

${ }^{*}$ CKD indicates chronic kidney disease

blood pressure (Table 2). Both groups were successful in achieving an improvement of their lipid profiles over time, with no significant difference between the CKD and non-CKD group (Table 2).

Post-CHD event ACE inhibitor use was lower and calcium channel blocker use was higher in those with CKD versus those without CKD (Table 3). There were no statistically significant differences patients with and without CKD in post-CHD event exposure to statins, $\beta$-blockers, and ARBs (Table 3).

The crude incidence of any hospitalized recurrent cardiovascular event (e.g., acute myocardial infarction, angina, coronary revascularization, peripheral arterial disease and stroke) and death were higher in CKD versus non-CKD patients (13.9 versus 11.5 per 100 personyears respectively, $\mathrm{P}<0.001$ ) (Table 4 ). In patients with CKD, there were a total of 307 total events $(\mathrm{N}=23$ acute myocardial infarction, $\mathrm{N}=32$ angina, $\mathrm{N}=98$ revascularization, $\mathrm{N}=51$ percutaneous coronary intervention, $\mathrm{N}=53$ coronary artery bypass surgery, $\mathrm{N}=9$ stroke, $\mathrm{N}=5$ peripheral vascular disease and $\mathrm{N}=36$ death) during follow-up. In patients without CKD, there were a total of 1,808 events $(\mathrm{N}=86$ acute myocardial infarction, $\mathrm{N}=187$ angina, $\mathrm{N}=663$ revascularization, $\mathrm{N}$ = 446 percutaneous coronary intervention, $\mathrm{N}=260$ coronary artery bypass surgery, $\mathrm{N}=56$ stroke, $\mathrm{N}=17$ peripheral vascular disease and $\mathrm{N}=93$ death) during follow-up.
Compared with eGFR $\geq 60 \mathrm{ml} / \mathrm{min} / 1.73 \mathrm{~m}^{2}$, those in lower eGFR categories had higher relative rates of recurrent cardiovascular events or death (Table 5). After adjustment for patient characteristics (Model 2) and comorbid conditions (Model 3), the hazard ratio for recurrent cardiovascular event or death decreased for eGFR $45-59 \mathrm{ml} / \mathrm{min} / 1.73 \mathrm{~m}^{2}$ and eGFR $<45 \mathrm{ml} / \mathrm{min} /$ $1.73 \mathrm{~m}^{2}$. Finally, after further adjustment for statin, $\beta$ blocker, calcium channel blocker, ACE inhibitor or $A R B$, there were no longer significant associations for eGFR $45-59 \mathrm{ml} / \mathrm{min} / 1.73 \mathrm{~m}^{2}$ or eGFR $<45 \mathrm{ml} / \mathrm{min} / 1.73$ $\mathrm{m}^{2}$ (Table 5).

\section{Discussion}

Among a unique, well-characterized cohort of persons with incident CHD, we evaluated whether differential cardiovascular medication use may explain, at least in part, the excess risk of recurrent cardiovascular disease events and death in CKD patients with incident CHD. We found that in adults with newly recognized CHD, those with pre-existing CKD were less likely to receive post-event ACE inhibitors and more likely to receive calcium channel blockers. Blood pressure and lipid levels improved in those with CKD during the follow-up period suggesting that study participants were aggressively treated and doses were optimized in those who did receive treatment. Mild (eGFR $45-59 \mathrm{ml} / \mathrm{min} / 1.73$ $\left.\mathrm{m}^{2}\right)$ and moderate $\left(\mathrm{eGFR}<45 \mathrm{ml} / \mathrm{min} / 1.73 \mathrm{~m}^{2}\right)$ CKD

Table 3 Post-coronary heart disease event exposure of cardiovascular medications by CKD status*

\begin{tabular}{|c|c|c|c|}
\hline Medication Class & $\begin{array}{l}\text { CKD }(\mathrm{N}=159) \\
\text { Medication Possession Ratio (SD) }\end{array}$ & $\begin{array}{l}\text { Non-CKD }(\mathrm{N}=1088) \\
\text { Medication Possession Ratio (SD) }\end{array}$ & P Value \\
\hline Statin & $\begin{array}{l}0.82(0.25) \\
N=155\end{array}$ & $\begin{array}{l}0.79(0.27) \\
N=1034\end{array}$ & 0.3 \\
\hline$\beta$-blockers & $\begin{array}{l}0.78(0.30) \\
N=146\end{array}$ & $\begin{array}{l}0.74(0.3) \\
N=1026\end{array}$ & 0.2 \\
\hline Calcium channel blockers & $\begin{array}{c}0.47(0.38) \\
N=80\end{array}$ & $\begin{array}{c}0.39(0.37) \\
N=350\end{array}$ & 0.06 \\
\hline Angiotensin converting enzyme inhibitors & $\begin{array}{l}0.50(0.39) \\
N=137\end{array}$ & $\begin{array}{l}0.58(0.38) \\
N=874\end{array}$ & 0.03 \\
\hline Angiotensin receptor blockers & $\begin{array}{c}0.50(0.35) \\
N=36\end{array}$ & $\begin{array}{c}0.52(0.34) \\
N=203\end{array}$ & 0.8 \\
\hline
\end{tabular}

${ }^{*}$ CKD indicates chronic kidney disease 
Table 4 Incidence (per 100 person-years) of recurrent cardiovascular events and death by CKD status*

\begin{tabular}{|c|c|c|}
\hline Cardiovascular Event & $\begin{array}{l}\text { CKD }(\mathrm{N}=159) \\
\text { Rate per } 100 \text { person years } \\
(95 \% \text { Confidence Interval) }\end{array}$ & $\begin{array}{c}\text { Non- CKD }(\mathrm{N}=1088) \\
\text { Rate per } 100 \text { person years } \\
(95 \% \text { Confidence Interval) }\end{array}$ \\
\hline Acute myocardial Infarction & 1.75 (1.10 to 2.62$)$ & 0.87 (0.70 to 1.08$)$ \\
\hline Angina & 2.44 (1.67 to 3.45$)$ & 1.96 (1.69 to 2.26$)$ \\
\hline Any revascularization & 10.15 (8.42 to 12.37$)$ & 9.58 (8.87 to 10.34$)$ \\
\hline Percutaneous coronary intervention & 4.25 (3.17 to 5.60$)$ & 5.50 (5.01 to 6.04) \\
\hline Coronary artery bypass surgery & 4.48 (3.35 to 5.86$)$ & 2.89 (2.54 to 3.26$)$ \\
\hline Stroke & 0.63 (0.29 to 1.21$)$ & 0.55 (0.42 to 0.71$)$ \\
\hline Peripheral arterial disease & 0.35 (0.11 to 0.82$)$ & $0.16(0.10$ to 0.26$)$ \\
\hline Death & 2.51 (1.76 to 3.47$)$ & 0.89 (0.73 to 1.10$)$ \\
\hline Any Event & $13.89(11.60$ to 16.51$)$ & 11.47 (10.68 to 12.32$)$ \\
\hline
\end{tabular}

${ }^{*}$ CKD indicates chronic kidney disease

were strong predictors for subsequent cardiovascular events and death even after adjustment for patient characteristics, but this association was no longer significant and had estimates near the null after additional adjustment for post-event cardiovascular medication use. These results suggest that the excess risk of recurrent cardiovascular events and death in patients with CKD may be explained, in part, by the differential use of cardiovascular medications. To our knowledge, no previously published study has examined whether differential medication exposure can explain the excess burden of recurrent cardiovascular disease in CKD patients with known CHD.

In our study, the overall improvement in blood pressure and lipid levels in those with CKD from baseline to the end of follow-up suggests that those who were treated with cardiovascular medications were treated aggressively. However, we found that those with CKD were less likely to receive ACE inhibitors which may be a reflection of concern of drug-related adverse effects, such as hyperkalemia or a hemodynamically mediated decrease in eGFR. The non-significant difference

Table 5 Hazard ratio of recurrent cardiovascular event or death in ADVANCE cohort by eGFR $(\mathrm{ml} / \mathrm{min} / 1.73 \mathrm{~m})^{2}$ *

\begin{tabular}{|c|c|}
\hline & $\begin{array}{l}\text { Hazard ratio }(95 \% \mathrm{Cl}) \text { of recurrent } \\
\text { cardiovascular event or death }\end{array}$ \\
\hline \multicolumn{2}{|l|}{ Model 1: Unadjusted Model } \\
\hline eGFR $>60$ & Referent \\
\hline eGFR 45-59 & 1.61 (1.18 to 2.18) \\
\hline eGFR $<45$ & 1.85 (1.19 to 2.89$)$ \\
\hline \multicolumn{2}{|c|}{$\begin{array}{l}\text { Model 2: Adjusted for age, sex, race/ethnicity, smoking, alcohol use, and physical } \\
\text { activity }\end{array}$} \\
\hline eGFR $>60$ & Referent \\
\hline eGFR 45-59 & $1.52(1.11$ to 2.10$)$ \\
\hline eGFR $<45$ & 1.70 (1.10 to 2.67$)$ \\
\hline \multicolumn{2}{|c|}{$\begin{array}{l}\text { Model 3: Model } 2+\text { adjusted for body mass index and history of diabetes and } \\
\text { hypertension }\end{array}$} \\
\hline eGFR $>60$ & Referent \\
\hline eGFR 45-59 & $1.47(1.10$ to 2.02$)$ \\
\hline eGFR $<45$ & 1.58 (1.00 to 2.50$)$ \\
\hline \multicolumn{2}{|c|}{ 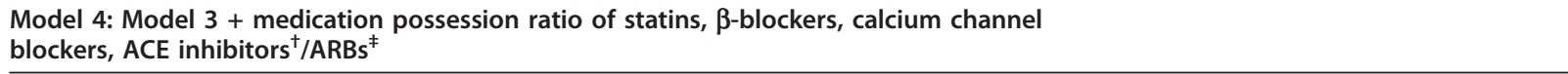 } \\
\hline eGFR $>60$ & Referent \\
\hline eGFR 45-59 & $0.82(0.25$ to 2.66$)$ \\
\hline eGFR $<45$ & $1.19(0.25$ to 5.58$)$ \\
\hline
\end{tabular}

*eGFR indicates glomerular filtration rate

TACE inhibitor indicates angiotensin converting enzyme inhibitor

¥ARB indicates angiotensin receptor blocker 
between post-event ARB exposure in those with CKD versus those without $C K D$ may be explained by the low overall use of ARBs in our sample. We observed no significant differences in the post-event receipt of statins and $\beta$-blockers between patients with or without preexisting CKD which is consistent with aggressive secondary prevention efforts among all patients within this health care setting. The higher use of calcium channel blockers among those with CKD is consistent with the fact that it is often more difficult to control blood pressure among CKD patients.

Several studies have found that selected cardiovascular medications appear to be beneficial in patients with CKD. The Study of Heart and Renal Protection (SHARP) randomly assigned patients with advanced CKD or ESRD to ezetimibe plus simvastatin and found a reduction in LDL cholesterol levels as well as a reduction in cardiovascular events with this combination therapy compared with placebo [32]. Several observational studies as well have observed lower rates of cardiovascular outcomes in those with known CHD and CKD who received statin therapy [33-36]. In a post hoc analysis of the Heart Outcomes Prevention Evaluation (HOPE trial), ramipril was associated with a lower incidence of subsequent cardiovascular events in both mild CKD and non-CKD patients [37]. In the Survival And Ventricular Enlargement (SAVE) trial, post-myocardial randomization to captopril resulted in a reduction of cardiovascular events, regardless of renal function [38]. In contrast, a study of more than 6,000 heart failure patients with varying levels of renal function found that while users of ACE inhibitors without CKD had lower mortality compared with those who did not receive ACE inhibitor therapy, receipt of ACE inhibitors was not associated with mortality differences in the subset of patients with CKD (adjusted OR 1.21, 95\% CI 0.97 to 1.51) [39]. However, the study participants had low ejection fraction, were followed for only 12 months and the study did not focus on incident ACE inhibitor therapy, raising the possibility of reverse causality or the presence of residual confounders (e.g. anemia, as hemoglobin data was not available). Studies have also found a survival benefit with $\beta$-blocker use in ESRD [40] and CKD [41]. The Bezafibrate Infarction Prevention (BIP) study found that in a cohort of 568 CKD patients with CHD, 43.1\% used beta-blockers at baseline and use of beta-blockers was associated with a reduction of the rate of acute myocardial infarction or sudden cardiac death [41]. Our study is consistent with these results and extends our knowledge by also studying the influence of other commonly prescribed cardiovascular medications within a diverse, community-based sample of newly diagnosed CHD. While previous studies have examined the use of a single cardiovascular medication, we were able to study multiple cardiovascular medications that are commonly prescribed together.

Our study had several strengths. Our study population was a large and diverse sample of well-characterized patients. We had up to seven years of longitudinal data on medication use for the study population and were able to accurately calculate a medication possession ratio. Our study had a few limitations as well. Information on longitudinal use of aspirin was unavailable in our study population. We also could not completely account for potential confounding by indication for selected medications. For example, we could not control for clinical decisions such as withholding an ACE inhibitor in a patient with hyperkalemia. As with any observational study, we cannot prove the causal role of postevent medication use on recurrent cardiovascular outcomes, but we attempted to control for known major confounders and found that the unfavorable association between pre-existing CKD and outcomes was no longer significant after adjustment for post-event receipt of cardiovascular medications. Finally, we conducted our study among health plan members within a large integrated health care delivery system in northern California, so our findings may not be completely generalizable to other health care settings or to uninsured patients.

\section{Conclusions}

In conclusion, our study suggests that differential cardiovascular medication use after an incident coronary heart disease event may explain, at least in part, the excess risk of recurrent cardiovascular events and death in patients with pre-existing chronic kidney disease. Although further randomized trials are needed to explore this association, our results suggest that patients with chronic kidney disease are at high risk for recurrent cardiovascular events and death and that more systematic use of selected cardiovascular medication may help to significantly attenuate this risk.

\section{Acknowledgements}

This research was supported by the American Kidney Fund (NB); the Donald W. Reynolds Foundation (AG); the NIDDK (NB); and the NHLBI (AG). The funding agencies were not involved in the study design, data analysis, writing of the manuscript or submission of the manuscript for publication.

\section{Author details}

'Department of Medicine, University of California, San Francisco, San Francisco, CA, USA. ²Division of Research, Kaiser Permanente of Northern California, Oakland, CA, USA. ${ }^{3}$ Department of Medicine, Stanford University, Palo Alto, CA, USA.

\section{Authors' contributions}

NB was involved in conception and design of the study, data analysis, manuscript preparation and approved the final manuscript. CYH was involved in the conception and design of the study, data analysis, manuscript prepartion and approved the final manuscript. MC was involved in the acquisition of data, analysis of data, interpretation of data, manuscript preparation and approved the final manuscript. Cl was involved in the data 
analysis, interpretation of data, manuscript preparation and approved the final manuscript. SP was involved in the data analysis, interpretation of data, manuscript preparation and approved the final manuscript. MH was involved in the data analysis, interpretation of data, manuscript preparation and approved the final manuscript. AG was involved in conception and design of the study, data acquisition, data analysis, manuscript preparation and approved the final manuscript

\section{Competing interests}

The authors declare that they have no competing interests.

Received: 3 March 2011 Accepted: 14 September 2011

Published: 14 September 2011

\section{References}

1. Foley RN, P P, Sarnak MJ: Clinical Epidemiology of Cardiovascular Disease in Chronic Renal Disease. Am J of Kid Dis 1998, 32:s112-119.

2. Herzog CA, MJaCA : Poor Long Term Survival After Acute Myocardial Infarction Among Patients on Long Term Dialysis. NEJM 1998, 339(12):799-805

3. Manjunath $G, T H$, Coresh J, et al: Level of Kidney Function as a Risk Factor for Cardiovascular Outcomes in the Elderly. Kid International 2003, 63:1121-1129.

4. Manjunath $G, T H$, Ibrahim $H$, et al: Level of Kidney Function as a Risk Factor for Atherosclerotic Cardiovascular Outcomes in the Community. J of Am Coll of Cardiol 2003, 41:47-55.

5. Weiner DE, T H, Amin MG, Stark PC, et al: Chronic Kidney Disease as a Risk Factor for Cardiovascular Disease and All-Cause Mortality: A Pooled Analysis of Community-Based Studies. J Am Soc Nephrol 2004, 15:1307-1315.

6. Reddan DN, Szczech L, Bhapkar MV, Moliterno DJ, Califf RM, Ohman EM, Berger PB, Hochman JS, Van de Werf F, Harrington RA, et al: Renal function, concomitant medication use and outcomes following acute coronary syndromes. Nephrol Dial Transplant 2005, 20(10):2105-2112.

7. Bailie GR, E G, Liu L, Roys R, Kiser M, et al: Patterns of Medication Use in the RRI-CKD Study: Focus on Medications with Cardiovascular Effects. Nephrol Dial Transplant 2005, 20:1110-1115.

8. Hsu CY, B D, Kuperman BJ, Curhan GC: Blood Pressure and Angiotensin Converting Enzyme Inhibitor Use in Hypertensive Patients with Chronic Renal Insufficiency. Am J Hypertens 2001, 14:1219-1225.

9. Tonelli M, Gill J, Pandeya S, Bohm C, Levin A, Kiberd BA: Barriers to blood pressure control and angiotensin enzyme inhibitor use in Canadian patients with chronic renal insufficiency. Nephrol Dial Transplant 2002, 17(8):1426-1433.

10. Fox CS, Muntner P, Chen AY, Alexander KP, Roe MT, Cannon CP, Saucedo JF, Kontos MC, Wiviott SD: Use of evidence-based therapies in short-term outcomes of ST-segment elevation myocardial infarction and non-ST-segment elevation myocardial infarction in patients with chronic kidney disease: a report from the National Cardiovascular Data Acute Coronary Treatment and Intervention Outcomes Network registry. Circulation 2010, 121(3):357-365.

11. Patel UD, Ou FS, Ohman EM, Gibler WB, Pollack CV, Peterson ED, Roe MT: Hospital performance and differences by kidney function in the use of recommended therapies after non-ST-elevation acute coronary syndromes. Am J Kidney Dis 2009, 53(3):426-437.

12. Berger AK, D S, Krumholz HM: Aspirin, Beta-Blocker, and angiotensinconverting enzyme inhibitor therapy in patients with end-stage renal disease and an acute myocardial infarction. J Am Coll Cardiol 2003, 42(2):209-210.

13. Reddan DN, S L, Bhapkar MV, Moliterno DJ, et al: Renal Function, concomitant medication use and outcomes following acute coronary syndromes. Nephrol Dial Transplant 2005, 20:2105-2112.

14. Winkelmayer WC, Levin R, Setoguchi S: Associations of kidney function with cardiovascular medication use after myocardial infarction. Clin J Am Soc Nephrol 2008, 3(5):1415-1422.

15. Latif F, Kleiman NS, Cohen DJ, Pencina MJ, Yen CH, Cutlip DE, Moliterno DJ, Nassif D, Lopez JJ, Saucedo JF: In-hospital and 1-year outcomes among percutaneous coronary intervention patients with chronic kidney disease in the era of drug-eluting stents: a report from the EVENT (Evaluation of Drug Eluting Stents and Ischemic Events) registry. JACC Cardiovasc Interv 2009, 2(1):37-45.
16. Beattie JN, Soman SS, Sandberg KR, Yee J, Borzak S, Garg M, McCullough PA: Determinants of mortality after myocardial infarction in patients with advanced renal dysfunction. Am J Kidney Dis 2001, 37(6):1191-1200.

17. McCullough PA, Sandberg KR, Borzak S, Hudson MP, Garg M, Manley HJ: Benefits of aspirin and beta-blockade after myocardial infarction in patients with chronic kidney disease. Am Heart J 2002, 144(2):226-232.

18. Go AS, Chertow GM, Fan D, McCulloch CE, Hsu CY: Chronic kidney disease and the risks of death, cardiovascular events, and hospitalization. $N$ Engl J Med 2004, 351(13):1296-1305.

19. Foley RN, Murray AM, Li S, Herzog CA, McBean AM, Eggers PW, Collins AJ: Chronic kidney disease and the risk for cardiovascular disease, renal replacement, and death in the United States Medicare population, 1998 to 1999. J Am Soc Nephrol 2005, 16(2):489-495.

20. Herzog CA, Ma JZ, Collins AJ: Poor long-term survival after acute myocardial infarction among patients on long-term dialysis. N Engl J Med 1998, 339(12):799-805.

21. McCullough PA: Why is chronic kidney disease the "spoiler" for cardiovascular outcomes? J Am Coll Cardiol 2003, 41(5):725-728.

22. Arellano MG, Petersen GR, Petitti DB, Smith RE: The California Automated Mortality Linkage System (CAMLIS). Am J Public Health 1984, 74(12):1324-1330.

23. Go AS, Iribarren C, Chandra M, Lathon PV, Fortmann SP, Quertermous T, Hlatky MA: Statin and beta-blocker therapy and the initial presentation of coronary heart disease. Ann Intern Med 2006, 144(4):229-238.

24. Levey AS, Coresh J, Greene T, Stevens LA, Zhang YL, Hendriksen S, Kusek JW, Van Lente F: Using standardized serum creatinine values in the modification of diet in renal disease study equation for estimating glomerular filtration rate. Ann Intern Med 2006, 145(4):247-254.

25. Levey AS, B J, Lewis JB, Greene T, Rogers N, Roth D: A more accurate method to estimate glomerular filtration rate from serum creatinine: a new prediction equation. Modification of Diet in Renal Disease Study Group. Ann Intern Med 1999, 130:461-470.

26. Levey AS, de Jong PE, Coresh J, Nahas ME, Astor BC, Matsushita K, Gansevoort RT, Kasiske BL, Eckardt KU: The definition, classification, and prognosis of chronic kidney disease: a KDIGO Controversies Conference report. Kidney Int 2011, 80(1):17-28.

27. Peterson AM, Nau DP, Cramer JA, Benner J, Gwadry-Sridhar F, Nichol M: A checklist for medication compliance and persistence studies using retrospective databases. Value Health 2007, 10(1):3-12.

28. Sikka R, Xia F, Aubert RE: Estimating medication persistency using administrative claims data. Am J Manag Care 2005, 11(7):449-457.

29. Hess LM, Raebel MA, Conner DA, Malone DC: Measurement of adherence in pharmacy administrative databases: a proposal for standard definitions and preferred measures. Ann Pharmacother 2006, 40(78):1280-1288.

30. Go ASIC, Chandra M, et al: Statin and B-Blocker Therapy and the Initial Presenation of Coronary Artery Disease. Annals of Internal Medicine 2006, 144(4):229-238.

31. Alexander M, Tekawa I, Hunkeler E, Fireman B, Rowell R, Selby JV, Massie BM, Cooper W: Evaluating hypertension control in a managed care setting. Arch Intern Med 1999, 159(22):2673-2677.

32. Sharp Collaborative G: Study of Heart and Renal Protection (SHARP): randomized trial to assess the effects of lowering low-density lipoprotein cholesterol among 9,438 patients with chronic kidney disease. Am Heart J 2010, 160(5):785-794, e710.

33. Shepherd J, Kastelein JJ, Bittner V, Deedwania P, Breazna A, Dobson S, Wilson DJ, Zuckerman A, Wenger NK: Intensive lipid lowering with atorvastatin in patients with coronary heart disease and chronic kidney disease: the TNT (Treating to New Targets) study. J Am Coll Cardiol 2008, 51(15):1448-1454.

34. Harada RK, Eagle KA, Kline-Rogers EM, Fang J, Smith D, Mukherjee D: Low utilization of secondary preventive medications and its potential impact in patients with chronic kidney disease and acute coronary syndromes. Indian Heart J 2006, 58(3):222-229.

35. Kendrick J, Shlipak MG, Targher G, Cook T, Lindenfeld J, Chonchol M: Effect of lovastatin on primary prevention of cardiovascular events in mild CKD and kidney function loss: a post hoc analysis of the Air Force/Texas Coronary Atherosclerosis Prevention Study. Am J Kidney Dis 2010, 55(1):42-49. 
36. Koren MJ, Davidson MH, Wilson DJ, Fayyad RS, Zuckerman A, Reed DP: Focused atorvastatin therapy in managed-care patients with coronary heart disease and CKD. Am J Kidney Dis 2009, 53(5):741-750.

37. Mann JF, Gerstein HC, Pogue J, Bosch J, Yusuf S: Renal insufficiency as a predictor of cardiovascular outcomes and the impact of ramipril: the HOPE randomized trial. Ann Intern Med 2001, 134(8):629-636.

38. Tokmakova MP, Skali H, Kenchaiah S, Braunwald E, Rouleau JL, Packer M, Chertow GM, Moye LA, Pfeffer MA, Solomon SD: Chronic kidney disease, cardiovascular risk, and response to angiotensin-converting enzyme inhibition after myocardial infarction: the Survival And Ventricular Enlargement (SAVE) study. Circulation 2004, 110(24):3667-3673.

39. Ezekowitz J, McAlister FA, Humphries KH, Norris CM, Tonelli M, Ghali WA, Knudtson ML: The association among renal insufficiency, pharmacotherapy, and outcomes in 6,427 patients with heart failure and coronary artery disease. J Am Coll Cardiol 2004, 44(8):1587-1592.

40. Foley RN, Herzog CA, Collins AJ: Blood pressure and long-term mortality in United States hemodialysis patients: USRDS Waves 3 and 4 Study. Kidney Int 2002, 62(5):1784-1790.

41. Chonchol M, Benderly M, Goldbourt U: Beta-blockers for coronary heart disease in chronic kidney disease. Nephrol Dial Transplant 2008, 23(7):2274-2279.

\section{Pre-publication history}

The pre-publication history for this paper can be accessed here: http://www.biomedcentral.com/1471-2369/12/44/prepub

doi:10.1186/1471-2369-12-44

Cite this article as: Bansal et al:: Potential role of differential medication use in explaining excess risk of cardiovascular events and death associated with chronic kidney disease: A cohort study. BMC Nephrology 2011 12:44

\section{Submit your next manuscript to BioMed Central} and take full advantage of:

- Convenient online submission

- Thorough peer review

- No space constraints or color figure charges

- Immediate publication on acceptance

- Inclusion in PubMed, CAS, Scopus and Google Scholar

- Research which is freely available for redistribution

Submit your manuscript at www.biomedcentral.com/submit 